\title{
Influence of Sociodemographic Characteristics on Non-Clinical Depressive Symptomatology among Portuguese Population
}

\section{A Influência das Características Sociodemográficas na Sintomatologia Depressiva Não-Clínica na População Portuguesa Cognitivamente Saudável}

\author{
Dandra Freitas 1,*, (D) Joana Nogueira 1, Paula Pinto 2, (D) Bianca Gerardo 1, Lara Alves ${ }^{1}$, (D) Isabel Santana 3 , \\ (D) Mário R Simões ${ }^{1}$ \\ 1-FPCE-UC, Center for Research in Neuropsychology and Cognitive and Behavioral Intervention (CINEICC) / Universidade de Coimbra, \\ Coimbra, Portugal \\ 2-Psychological Assessment Lab., Faculty of Psychology and Educational Sciences, University of Coimbra / Universidade de Coimbra, \\ Coimbra, Portugal \\ 3-Neurology Unit, Centro Hospitalar e Universitário de Coimbra, Coimbra, Portugal; e Faculty of Medicine / Universidade de Coimbra, \\ Coimbra, Portugal
}

DOI: https://doi.org/10.46531/sinapse/AO/200016/2021

Informações/Informations: Artigo Original, publicado em Sinapse, Volume 21, Número 1, janeiro-março 2021. Versão eletrónica em www.sinapse.pt Original Article, published in Sinapse, Volume 21, Number 1 january-march 2021. Electronic version in www.sinapse.pt (C) Autor (es) (ou seu (s) empregador (es)) e Sinapse 2021. Reutilização permitida de acordo com CC BY-

NC. Nenhuma reutilização comercial.

(C) Author(s) (or their employer(s)) and Sinapse 2021. Re-use permitted under CC BY NC. No commercial re-use.

Keywords:

Aged;

Cognition;

Depression;

Neuropsychological Tests;

Portugal;

Socioeconomic Factors.

\section{Palavras-chave:}

Cognição;

Depressão;

Factores Socioeconómicos:

Idoso:

Portugal;

Testes Neuropsicológicos.

\footnotetext{
*Autor Correspondente Corresponding Author: Sandra Cristina Lopes Freitas Faculdade de Psicologia e de Ciências da Educação, Rua do Colégio Novo, 3000-115 Coimbra, Portugal sandrafreitas0209@gmail.com
}

Recebido / Received: 2020-04-23 Aceite / Accepted: 2021-03-26 Publicado / Published: 2021-04-16

\section{Abstract}

Introduction: Depression is the most frequent psychiatric disorder with several negative consequences on health, emotional well-being, and quality of life. Regarding the increased risk of comorbidities in population due to depression, the identification of vulnerable characteristics for depressive symptomatology is crucial to decrease this worldwide cause of disability. We aim to analyze the relationship between sociodemographic characteristics and depressive symptomatology among non-depressed to mildly-depressed cognitively healthy adults and older individuals' residents in the community.

Material and Methods: We used a community-based sample ( $N=850$; mean age $=57.34 \pm 15.20$, age range $=[25-91]$; mean education $=7.89 \pm 4.56$, education range $=[2-27])$ that was stratified into the main sociodemographic variables (age, gender, educational level, geographic region, geographic localization, and residence area). The distribution by these strata is similar to that verified in the Portuguese population, thus the study sample can be considered representative of the general population. To measure depressive symptomatology, we applied the Geriatric Depression Scale - 30 (GDS-30).

Results: Among the sociodemographic variables, gender had the largest effect size on the GDS-30 total scores $\left(\eta p^{2}=0.061\right)$, followed by educational level $\left(\eta p^{2}\right.$ $=0.027)$ and employment status $\left(\eta p^{2}=0.019\right)$. We found the association between female gender, low educational level, inactive employment status, and residence in inland geographic localization, as a possible pattern for higher depressive symptomatology in the Portuguese population.

Discussion: This study revealed a vulnerable pattern of sociodemographic characteristics related to depressive symptomatology among Portuguese non-depressed to mildly-depressed cognitively healthy adults and older individuals.

\section{Resumo}

Introdução: A depressão é uma doença psiquiátrica com várias consequências negativas para a saúde, bem-estar emocional e qualidade de vida. De acordo com o aumento do risco de comorbidades na população devido à depressão, a identificação de padrões de vulnerabilidade para o desenvolvimento de sintomatologia de- 
pressiva é crucial para a diminuição e controlo desta condição e suas consequências. Pretende-se analisar a relação entre as variáveis sociodemográficas entre participantes cognitivamente saudáveis (não deprimidos ou com sintomatologia depressiva ligeira) residentes na comunidade.

Material e Métodos: Foi utilizada uma amostra comunitária $(\mathrm{N}=850$; idade $=$ 57,34 \pm 15,20, [mínimo: 25, máximo: 91]; escolaridade $=7,89 \pm 4,56$, [mínimo: 2, máximo: 27]) que foi estratificada de acordo com as seguintes variáveis sociodemográficas: idade, género, escolaridade, região e localização geográfica, e área de residência. A distribuição por estes estratos foi semelhante à observada na população portuguesa, pelo que esta esta amostra pode ser considerada como sendo representativa da população geral. Como medida de sintomatologia depressiva foi utilizada a Escala de Depressão Geriátrica - 30 (GDS-30).

Resultados: Entre as variáveis sociodemográficas, o género teve maior tamanho de efeito nos resultados totais da GDS-30 $\left(\eta p^{2}=0,061\right)$, seguido da educação $\left(\eta p^{2}=\right.$ $0,027)$ e da atividade profissional $\left(\eta p^{2}=0,019\right)$. A associação entre o género feminino, baixos níveis de escolaridade, inatividade profissional e residência no interior de Portugal, foi apontada como um possível padrão de vulnerabilidade para níveis mais elevados de sintomatologia depressiva.

Discussão: Este estudo permitiu identificar padrões de vulnerabilidade de características sociodemográficas para sintomatologia depressiva entre adultos e idosos cognitivamente saudáveis (não deprimidos ou com sintomatologia depressiva ligeira) na população portuguesa.

\section{Introduction}

Depression is the most frequent psychiatric disorder in adults and older people and the large cause of disability worldwide, threatening both personal psychological and physical characteristics, affecting the emotional well-being and quality of life. ${ }^{1,2}$

Several studies establish a relationship between sociodemographic characteristics and depression, addressing depressed individuals as more likely to be older, of the female gender, less educated, less integrated in the community, of lower socioeconomic status, and with fewer families ties. ${ }^{3-5}$

Additionally, some evidence suggest that social support is higher among those who are younger, married and of higher socioeconomic and employment status. The risk of mistreatment and depression also seems to be higher among people who are unemployed and dependent of social support. ${ }^{6,7}$

Moreover, depression has also been associated with marital status, wherein adults who are single or divorced tend to report higher levels of depressive symptomatology, than adults who are married or who live with a family member. ${ }^{8-10}$
The relationship between less social integration and depression as a risk factor for cognitive decline is well established in literature. ${ }^{1-14}$

A reduced social and leisure activity increases the likelihood to have late-life depression, which works adversely for a successful aging process. Additionally, depression has several somatic consequences, such as the increased risk for cardiovascular diseases, stroke, and diabetes, probably due to a deregulation and frailty of the biological mechanisms.

Given these comorbidities and functional disabilities, and considering the evidence of depression as a negative influence for successful aging, it is important to orientate health policies and communities to this target, namely with the implementation of screening programs to early detection and better characterization of emotional disorders, which is crucial and demanding. ${ }^{15,16}$

However, depression is still commonly underestimated and undiagnosed, due to the tendency for older people to minimize psychological symptomatology or physiological related symptoms. ${ }^{18}$ The prevalence and incidence of this psychiatric disorder vary according to the differences in settings and cultures. In Portugal, the 
community-based study of Vaz-Serra and Firmino (I 989) reported significant depressive symptoms in $17 \%$ of the general population. ${ }^{17}$

In turn, the Epidemiological National Study on Mental Health of Caldas de Almeida and Xavier (2013) highlighted an annual prevalence rate of $6.8 \%$ for major depression, with $11.7 \%, 59 \%$ and $29.3 \%$ of the cases being of mild, moderate and heightened severity, respectively. ${ }^{19}$

Sousa and colleagues $(2010)$ showed a prevalence of $42 \%$ of depression among older adults. Furthermore, in our country, an association was established between depression and the female gender, lower educational levels, and the unmarried status. ${ }^{20}$

In a sample of 240I Portuguese community dwellings adults and older adults, Oliveira-Brochado and colleagues classified, according to Beck Depression Inventory$-\mathrm{II}, 15 \%$ of the sample as with mild depression, $9 \%$ as with moderate depression and $6 \%$ as severe depression cases, and reported higher symptomatology in the female gender. ${ }^{21}$

More recently, Gonçalves-Pereira and colleagues (2019) registered a prevalence rate of depression of $18 \%$ among older adults with ages above 65 years, according to the EURO depressive symptoms scale. ${ }^{22,23}$

There are several methods to assess depressive symptomatology according to sociodemographic variables, medical history, and context. In Portugal, the evaluation of depression in community dwellings adults and older subjects has been made through three frameworks: i) a psychological approach where depressive and anxiety symptoms are assessed with scales as the Geriatric Depression Scale (GDS long or short versions) $)^{24-26}$ and the Geriatric Anxiety Inventory (GAI), ${ }^{27-29}$ respectively; ii) a neuropsychological approach where the main interest is the subjective or objective impact of depressive symptoms in global cognitive functioning and in the main cognitive domains, using, for instance, the Subjective Memory Complaints (SMC), ${ }^{30,31}$ the Addenbrooke's Cognitive Examination-revised (ACE$-\mathrm{R}),{ }^{26,32}$ the Mini-Mental State Examination (MMSE), ${ }^{33,34}$ or the Montreal Cognitive Assessment (MoCA) ${ }^{35,36}$; iii) a clinical approach, within which is performed an integration of the psychological profile and several comorbidities and/or other diagnosed conditions.'

The present study aims to analyze the relationship between sociodemographic characteristics and depressive symptomatology [according to the GDS-30 score] among non-depressed to mildly-depressed cognitively healthy adults and older individuals through a large Portuguese community-based sample, stratified according to the main sociodemographic variables of the general population.

\section{Methods}

\section{Participants and Procedures}

The investigation was carried out in a community-based sample that is representative of the Portuguese population, and which was used in a previous normative study published by our research group. ${ }^{37}$ The participants, aged 25 years and older, were recruited at national health and social security services and resided in all geographic regions Portugal (continental territory). The inclusion criteria considered in the initial subjects selection were the following: (a) minimum age of 25 years; (b) being a native speaker of Portuguese and having schooling in Portugal; (c) absence of significant motor, visual or auditory deficits, all of which may influence performance on tests. To ensure that participants were cognitively healthy adults, the following exclusion criteria were also defined: (I) evidence of loss of autonomy in daily living activities; (2) history of alcoholism or substance abuse; (3) relevant neurological or psychiatric diseases or chronic unstable systemic disorders that impact cognition; (4) medication with a possible impact in cognition (e.g., psychotropic or psycho-active drugs); (5) GDS-30 total score $\geq 2$ I (originally classified as "severe depression"). ${ }^{24}$ To confirm these general criteria, all subjects were interviewed by a psychologist with a standard questionnaire including a complete sociodemographic characterization, an inventory of the current clinical health status, and the collection of past habits and medical history. For older subjects, this information was also confirmed by a general practitioner, community center directors, and/or an informant (an individual in co-habitation or a close relative). Subjects only responded to the GDS-30 if previously "included" upon interview. Finally, for further inclusion in the study, all subjects were required to display normal cognitive performance on the assessment battery used in the present study (see "Materials"), considering the Portuguese cut-off points. ${ }^{37-40}$

Each participant was assessed in a single session by one of two psychologists' experts in neuropsychological assessment. This study was approved by the local ethics committee and all participants gave written informed consent prior to participation. For patients who were not capable of providing informed consent, a legal re- 
presentative fulfilled this requirement on their behalf.

From the initial community-based sample of the I I87 subjects, 337 subjects (28.4\%) were excluded after the interview (due to positive history of neurological or psychiatric disorder). The final sample comprised 850 cognitively healthy adults that met all the inclusion criteria and whose GDS-30 scores were 20 points or less. The stratification according to sociodemographic variables confirmed that this final sample was representative of the distribution observed in the Portuguese population (Table 1).

\section{Material}

The battery for the evaluation of each participant included the following instruments: (i) Complete a sociodemographic questionnaire; (ii) Inventory of current clinical health status; (iii) Inventory of past habits and medical history; (iv) Irregular Word Reading Test (TeLPI: Teste de Leitura de Palavras Irregulares);

(v) Mini-Mental State Examination (MMSE) ${ }^{37}$;

(vi) Montreal Cognitive Assessment (MoCA $)^{33,34}$;

(vii) Clinical Dementia Rating scale (CDR) ${ }^{35,36}$;

(viii) Subjective Memory Complaints scale (SMC) ${ }^{38,41}$;

(ix) Geriatric Depression Scale - 30 (GDS-30)..$^{30,31}$

The GDS-30 was the measure used in the present investigation to assess depressive symptomatology. ${ }^{25,36}$

This is a brief scale composed of 30 dichotomous response questions designed to assess emotional and behavioral symptoms of depression in adults and older people (score range $=[0-30$ points $] ; 3$ classifications: normal/without clinically relevant depressive symptomatology [0 to 10 points], mild depression [II to 20 points], severe depression [more than 21 points]). In this study, we only targeted non-depressed to mildly-depressed subjects. Thus, individuals who scored 21 points or more were excluded. ${ }^{24,25}$

\section{Variable Definitions and Sample Stratification}

To ensure the representativeness of the observed distribution in the Portuguese population, the sample of 850 subjects was stratified according to the following sociodemographic variables: (a) age [3 age intervals: 25 - 49 (“young adults"), 50 - 64 (“adults"), and $\geq 65$ (“elderly")]; (b) gender [female/male]; (c) educational level [4 educational levels, according to the number of school years successfully completed in the Portuguese educational system: I - 4 (primary education), 5 - 9 (midd- le school), I0 - I2 (high school), over 12 (university/ college); these categories correspond to the Portuguese educational system]; (d) geographic region [according to the NUTS-Il classification, the Portuguese continental territory is divided into 5 geographic regions: North, Centre, Lisbon, Alentejo, and Algarve] ${ }^{42}$; (e) geographic localization [2 geographic localizations were considered: coast and inland]; ( $f$ ) residence area [according to the Types of Urban Areas, 3 categories were considered: predominantly urban areas (PUA), moderately urban areas (MUA), and predominantly rural areas (PRA)]. ${ }^{42}$

In the present study, we further included the following sociodemographic and health variables (which were not criteria for sample stratification): (I) marital status [classified as "single" (single, divorced or widowed subjects) or "married" (married or cohabiting couples in a civil union)]; (2) employment status [classified as "active" (subjects with ongoing professional activities) or "inactive" (unemployed, retired, or domestic subjects)].

\section{Statistical Analysis}

All data analyses were conducted using the Statistical Package for the Social Sciences, (SPSS, version 22.0).

Descriptive statistics were computed for all sociodemographic variables. Cronbach's alpha coefficients and the observed correlations (using the Pearson and Spearman correlation coefficients) were also calculated. ${ }^{43}$

To investigate the significance of age (in years), education (years of schooling successfully completed) and other variables as influencing factors of the GDS-30 total scores, simple and multiple linear regression (SLR; MLR) analyses were performed, using the enter method, and the coefficient of determination $\left(R^{2}\right)$ was considered as an estimate of the effect size of the regression models. ${ }^{44}$ The differences in the GDS-30 total scores between subgroups stratified according to sociodemographic variables were examined using analysis of covariance (ANCOVA), controlled for the covariates age and educational level. Partial eta squared $\left(\eta \mathrm{P}^{2}\right)$ was used as an estimate of the effect size. ${ }^{44}$

\section{Results}

\section{Sample Characteristics and Stratification}

The total sample included 850 cognitively healthy subjects (mean age $=57.34 \pm 15.20$, age range $=[25-$ 9I]; mean education $=7.89 \pm 4.56$, education range $=$ [2 - 27]). Table 1 shows the detailed sociodemographic 
characterization of the sample, considering the stratification variables as well as the other sociodemographic variables considered in this study. The distribution of the study sample by the several strata was comparable to that observed in the target Portuguese population.

\section{Psychometric Analyses}

Regarding the internal consistency of the GDS-30, the Cronbach's alpha observed was 0.86 for the total study sample. Analysis of the potential elimination of items to increase internal consistency revealed that none of the GDS-30 items should be excluded.

At the construct validity level, statistically significant correlations were observed between each item and the GDS-30 total score $(p<0.01)$, ranging between $r=0.14$ and $r=0.70$.

Correlation analyses revealed statistically significant associations between the GDS-30 total scores and education $(r=-0.156, p<0.001)$, gender $(\rho=-0.229, p<$

Table 1. Sociodemographic characterization and stratification of the study sample.

\begin{tabular}{|c|c|c|c|c|c|}
\hline & \multirow[t]{2}{*}{ Levels } & \multicolumn{2}{|c|}{ Sample } & \multicolumn{2}{|c|}{ Portugal } \\
\hline & & $\mathbf{n}$ & $\%$ & $\mathrm{n}$ & $\%$ \\
\hline \multicolumn{6}{|c|}{ Sociodemographic stratification of sample } \\
\hline \multirow[t]{3}{*}{ Age } & $25-49$ & 226 & 26.6 & \multicolumn{2}{|c|}{-} \\
\hline & $50-64$ & 310 & 36.5 & \multicolumn{2}{|c|}{-} \\
\hline & $\geq 65$ & 314 & 36.9 & \multicolumn{2}{|c|}{-} \\
\hline \multirow[t]{2}{*}{ Gender } & Female & 491 & 57.8 & 3946 & 52.6 \\
\hline & Male & 359 & 42.2 & 3559 & 47.4 \\
\hline \multirow[t]{4}{*}{ Educational Level } & Primary & 345 & 40.6 & 2426 & 36.6 \\
\hline & Middle & 251 & 29.5 & 2280 & 34.4 \\
\hline & High & 122 & 14.4 & 960 & 14.5 \\
\hline & University & 132 & 15.5 & 956 & 14.5 \\
\hline \multirow[t]{5}{*}{ Geographic Region } & North & 338 & 39.8 & 2722 & 36.0 \\
\hline & Center & 235 & 27.6 & 1794 & 24.0 \\
\hline & Lisbon & 201 & 23.6 & 2091 & 28.0 \\
\hline & Alentejo & 53 & 6.2 & 577 & 8.0 \\
\hline & Algarve & 23 & 2.7 & 321 & 4.0 \\
\hline \multirow[t]{2}{*}{ Geographic Localization } & Coast & 724 & 85.2 & 6379 & 85.0 \\
\hline & Inland & 126 & 14.8 & 1126 & 15.0 \\
\hline \multirow[t]{3}{*}{ Residence Area } & PUA & 582 & 68.5 & 5103 & 68.0 \\
\hline & MUA & 140 & 16.5 & 1200 & 16.0 \\
\hline & PRA & 128 & 15.1 & 1200 & 16.0 \\
\hline \multicolumn{6}{|c|}{ Others Sociodemographic Variables } \\
\hline \multirow[t]{2}{*}{ Marital Status } & Married & 633 & 74.5 & \multicolumn{2}{|c|}{-} \\
\hline & Single & 217 & 25.5 & \multicolumn{2}{|c|}{-} \\
\hline \multirow[t]{2}{*}{ Employment Status } & Active & 414 & 48.7 & \multicolumn{2}{|c|}{-} \\
\hline & Inactive & 436 & 51.3 & \multicolumn{2}{|c|}{-} \\
\hline
\end{tabular}

PUA = predominantly urban areas; $\mathrm{MUA}=$ moderately urban areas; PRA = predominantly rural areas.

Note: The values $(n)$ of the Portuguese population are expressed in thousands and represent the data of the resident population in continental Portugal aged over 24 years (Instituto Nacional de Estatística, 2010). 
$0.001)$ and employment status $(\rho=0.151, p<0.001)$, but not between GDS-30 total scores and age $(r=0.056$, $p=0.1$ I4). Linear regression models were computed to examine the contributions of these variables on the GDS30 scores. While a model including age did not reach statistical significance $(p>0.05)$, linear models including educational level $(F(I, 797)=19.883, p<0.00 I)$, gender $(F(I, 797)=48.233, p<0.00 I)$ and employment status $(F(I, 797)=16.712, p<0.00 I)$ explained, respectively, $2.4 \%, 5.7 \%$ and $2.1 \%$ of the total variance on GDS-30 scores. A MLR model including all three predictors revealed to be significant $(F(3,795)=25.738, p<0.00 I)$

Table 2. Analysis of group differences on the GDS scores while controlling for the effect of covariates (age and education) and estimation of the effect sizes.

\begin{tabular}{|c|c|c|c|}
\hline Variables & $\begin{array}{l}\text { GDS } \\
M \pm S D\end{array}$ & $F(A N C O V A)$ & Effect Size \\
\hline \multicolumn{4}{|l|}{ Age } \\
\hline $25-49$ & $6.54 \pm 5.57$ & \multirow{3}{*}{$F_{(2844)}=0.178, p=0.837$} & \multirow{3}{*}{$\begin{array}{c}\text { Null } \\
\eta p^{2}=0.000\end{array}$} \\
\hline $50-64$ & $7.31 \pm 5.40$ & & \\
\hline$\geq 65$ & $7.21 \pm 5.17$ & & \\
\hline \multicolumn{4}{|l|}{ Gender } \\
\hline Female & $8.15 \pm 5.66$ & \multirow{2}{*}{$F_{(1844)}=51.990, p<0.001$} & \multirow{2}{*}{$\begin{array}{c}\text { Medium } \\
\eta p^{2}=0.061\end{array}$} \\
\hline Male & $5.55 \pm 4.55$ & & \\
\hline \multicolumn{4}{|c|}{ Educational Level } \\
\hline Primary & $7.47 \pm 5.39$ & \multirow{4}{*}{$F_{(4841)}=2.014, p=0.091$} & \multirow{4}{*}{$\begin{array}{c}\text { Small } \\
\eta p^{2}=0.010\end{array}$} \\
\hline Middle & $7.53 \pm 5.25$ & & \\
\hline High & $7.36 \pm 5.54$ & & \\
\hline University & $4.98 \pm 4.93$ & & \\
\hline \multicolumn{4}{|c|}{ Geographic Region } \\
\hline A. North & $7.13 \pm 5.40$ & \multirow{5}{*}{$F_{(4841)}=2.014, p=0.091$} & \multirow{5}{*}{$\begin{array}{c}\text { Small } \\
\eta p^{2}=0.010\end{array}$} \\
\hline B. Center & $7.01 \pm 5.37$ & & \\
\hline C. Lisbon & $7.39 \pm 5.49$ & & \\
\hline D. Alentejo & $6.19 \pm 4.38$ & & \\
\hline E. Algarve & $6.00 \pm 5.89$ & & \\
\hline \multicolumn{4}{|c|}{ Geographic Localization } \\
\hline Coast & $6.90 \pm 5.30$ & \multirow{2}{*}{$F_{(1844)}=3.948, p=0.047$} & \multirow{2}{*}{$\begin{array}{c}\text { Small } \\
\eta p^{2}=0.005\end{array}$} \\
\hline Inland & $8.01 \pm 5.75$ & & \\
\hline \multicolumn{4}{|c|}{ Residence Area } \\
\hline PUA & $6.86 \pm 5.27$ & \multirow{3}{*}{$F_{(2843)}=0.998, p=0.369$} & \multirow{3}{*}{$\begin{array}{c}\text { Small } \\
\eta p^{2}=0.003\end{array}$} \\
\hline MUA & $6.96 \pm 5.02$ & & \\
\hline PRA & $7.98 \pm 6.00$ & & \\
\hline \multicolumn{4}{|c|}{ Marital Status } \\
\hline Married & $6.99 \pm 5.25$ & \multirow{2}{*}{$F_{(1844)}=2.199, p=0.139$} & \multirow{2}{*}{$\begin{array}{c}\text { Null } \\
\eta p^{2}=0.003\end{array}$} \\
\hline Single & $7.29 \pm 5.74$ & & \\
\hline \multicolumn{4}{|c|}{ Employment Status } \\
\hline Active & $6.29 \pm 5.17$ & \multirow{2}{*}{$F_{(1844)}=15.593, p<0.001$} & \multirow{2}{*}{$\begin{array}{c}\text { Small } \\
\eta p^{2}=0.019\end{array}$} \\
\hline Inactive & $7.83 \pm 5.46$ & & \\
\hline
\end{tabular}

PUA = predominantly urban areas; MUA = moderately urban areas; PRA = predominantly rural areas; $M$ : mean; SD: standard deviation; $F$ : analysis of covariance (ANCOVA) values; $\eta p^{2}$ : partial eta squared values.

Note: According to Cohen (1988), $\eta p^{2}$ values of $0.01,0.06$ and 0.14 are considered small, medium and large effect sizes, respectively. 
and explained $8.9 \%$ of the GDS-30 variance. Of the three predictors, gender was the most relevant $(B=-0.235, t$ $=-6.879, p<0.001)$, followed by educational level $(B=$ $-0.140, t=-3.931, p<0.001)$ and employment status ( $B$ $=0.73, t=2.036, p=0.042)$.

\section{Group Differences}

The total study sample exhibited a mean GDS-30 global score of 7.06 points $(S D=5.37)$. Analysis of the sociodemographic subgroup differences on the GDS-30 total scores (controlled for the effect of age and education), and respective effect sizes, are presented in Table 2. With effect sizes ranging from small to medium, the GDS-30 total scores significantly differed across gender (female or male), educational level (primary, middle, high or university), geographic localization (coast or inland) and employment status (active or inactive).

\section{Discussion}

In the present study, we conducted a systematic analysis of the relationship between a large set of sociodemographic characteristics and the depressive symptomatology of non-depressed to mildly-depressed cognitively healthy adults and older dwellings. For this purpose, we used a large Portuguese community-based sample, stratified according to the main sociodemographic variables of the population (age, gender, educational level, geographic region, geographic localization, and residence area). Since we intended to ensure a better equivalence between the study sample and the target population (to increase the confidence in the conclusions drawn), the distribution our group by these several sociodemographic strata was similar to that verified in the Portuguese population. Therefore, the study group can be considered as representative of our population.

Gender was the sociodemographic variable that revealed best predictive value $(\beta=-0.235)$ of, as well as a more marked effect size on the GDS-30 total scores $\left(\eta p^{2}=0.06 \mathrm{I}\right)$, followed by educational level $(B=$ $\left.-0.140 ; \eta p^{2}=0.027\right)$ and employment status $(B=0.73$, $\left.\eta p^{2}=0.019\right)$. This set of three variables revealed to be the most significant contributors to the explanation of the depressive symptomatology among non-depressed to mildly-depressed cognitively healthy adults and older individuals. The present results suggest that women with lower educational levels and an inactive employment status are the ones who reveal severer depressive symptomatology. This evidence supports previous studies with similar results, that report higher levels of mild depressive symptomatology among not only women, ${ }^{23}$ but less educated women. ${ }^{3-5}$

Conversely, age seems to not be associated with depressive symptoms. Indeed, it revealed to be a non-significant predictor of GDS-30 scores, and it did not have a significant effect on depressive symptomatology - no significant correlations were found between age and GDS nor differences in GDS-30 total scores were detected across the age groups. Although such results seem to contradict literature evidence that support a higher depression symptomatology among older people, ${ }^{3}$ they are in line with findings reported by Gonçalves-Pereira and colleagues (2019) that state the prevalence of depression as not age-dependent, according to three different diagnostic criteria. ${ }^{23}$ However, the relationship between age and symptoms of depression seems to not be completely established, as some studies suggest a negative relationship between age and depressive symptomatology when all risk factors are statistically controlled, despite the duration of depressive episodes being longer in older than younger individuals. ${ }^{45,46}$

Future studies should consider more comprehensive age groups as well as to extend the assessment methods for depressive symptoms in order to withdraw steadier conclusions regarding this topic. Similarly, our results did not corroborate the tendency observed in previous studies of a higher prevalence of symptomatology among unmarried individuals. In fact, in the present study, marital status was not significantly associated with the GDS30 total scores, and we did not find any significant effect of this variable in depressive symptomatology. ${ }^{8-10}$

In turn, investigation of geographical variables within a national context is complex. At the same time, international inter-studies comparisons are meaningless due to the specificities of territories and populations. ${ }^{47}$ To the best of our knowledge, there are no previous Portuguese studies where the influence of geographical variables on depressive symptoms had been evaluated, and therefore, these variables were included in the current study assuming an exploratory nature. Despite the geographic localization not sharing a significant correlation with depression symptoms, the results found regarding differences between groups reveal a statistically significant difference between subjects living in the coastal areas compared to subjects from inland areas, with a tendency for residents 
in the coastal areas to exhibit less depressive symptomatology. Further analysis included the Geographic Regions according to NUTS-II and Residence areas (predominantly urban or rural areas). Overall, the results did not reveal statistical significance, except a low mean GDS-30 score in southern regions (Alentejo and Algarve). These results seem to contradict previous evidence of a higher prevalence rates of depression in rural area, according to the EURO-D diagnostic criteria. ${ }^{23}$

A potential limitation of the present study may arise from the administration of the GDS-30 not only to older, but also to young adults, given this instrument was originally developed to assess depressive symptomatology among adults and older adults. However, the direct comparison between GDS-30 scores showed up as the better suited method to allow a cross-sectional analysis between the age groups included in the present study, since it guaranteed data comparability. In addition, the psychometric results obtained in the present study point to the usefulness and validity of administrating the GDS30 in other age groups besides the one for which this instrument was originally designed (elderly individuals). Additionally, our findings should be interpreted in the stringent context of the targeted population - non-depressed-to-mildly-depressed cognitively healthy individuals - and they should not be generalized to individuals with diagnosed clinical conditions. Further studies considering clinical groups with an operationalized psychiatric diagnosis will be essential to corroborate the presented findings, a framework unfeasible in the current study considering the national community context of this investigation. Furthermore, subsequent studies would benefit from a more extensive characterization of the severity of depressive symptoms with the inclusion of more specific and descriptive instruments.

\section{Conclusion}

The current study allowed the identification of the sociodemographic characteristics that more likely are related to depressive symptomatology among non-depressed to mildly-depressed cognitively healthy adults and older adults. Results highlight the association of features female gender, low educational level, inactive employment status, and residence in inland geographic localization as a vulnerable pattern for higher depressive symptomatology in the Portuguese population.

\section{Responsabilidades Éticas}

Conflitos de Interesse: Os autores declaram a inexistência de conflitos de interesse na realização do presente trabalho.

Fontes de Financiamento: Não existiram fontes externas de financiamento para a realização deste artigo.

Confidencialidade dos Dados: Os autores declaram ter seguido os protocolos da sua instituição acerca da publicação dos dados de doentes.

Proteção de Pessoas e Animais: Os autores declaram que os procedimentos seguidos estavam de acordo com os regulamentos estabelecidos pelos responsáveis da Comissão de Investigação Clínica e Ética e de acordo com a Declaração de Helsínquia da Associação Médica Mundial.

Proveniência e Revisão por Pares: Não comissionado; revisão externa por pares.

Ethical Disclosures

Conflicts of interest: The authors have no conflicts of interest to declare.

Financing Support: This work has not received any contribution, grant or scholarship

Confidentiality of Data: The authors declare that they have followed the protocols of their work center on the publication of data from patients.

Protection of Human and Animal Subjects: The authors declare that the procedures followed were in accordance with the regulations of the relevant clinical research ethics committee and with those of the Code of Ethics of the World Medical Association (Declaration of Helsinki).

Provenance and Peer Review: Not commissioned; externally peer reviewed.

\section{References / Referências}

1. Gustafson Y, Nogueira V, O'Dwyer S, Roller R, Egger TP, Firmino $\mathrm{H}$, et al. Depression in old age in Austria, Ireland, Portugal and Sweden. Eur Geriatr Med. 2013;4:202-8. doi:10.1016/j. eurger.2013.04.011.

2. World Health Organization. World report on aging and health. Geneve: WHO Press; 2015.

3. Barua A, Ghosh M, Kar N, Basilio M. Socio-demographic factors of geriatric depression. Indian J Psychol Med. 2010;32:87-92. doi:10.4103/0253-7176.78503.

4. Jerliu N, Toçi E, Burazeri G, Ramadani N, Brand H. Prevalence and socioeconomic correlates of chronic morbidity among elderly people in Kosovo: A population-based survey. BMC Geriatr. 2013;13:22. doi:10.1186/1471-2318-13-22.

5. Penninx BWJH, Leveille S, Ferrucci L, Van Eijk JTM, Guralnik JM. Exploring the effect of depression on physical disability: Longitudinal evidence from the established populations for epidemiologic studies of the elderly. Am J Public Health. 1999;89:1346-52. doi:10.2105/AJPH.89.9.1346.

6. Ansseau M, Fischler B, Dierick M, Albert A, Leyman S, Mignon A. Socioeconomic correlates of generalized anxiety disorder and major depression in primary care: the GADIS II study (Generalized Anxiety and Depression Impact Survey II). Depress Anxiety. 2008;25:506-13. doi: 10.1002/ da.20306.

7. Melchiorre MG, Chiatti C, Lamura G, Torres-Gonzales F, Stankunas M, Lindert J, et al. Social support, socio-economic status, health and abuse among older people in seven European countries. PLoS One. 2013;8:e54856. doi: 10.1371/journal.pone.0054856.

8. Kim HK, McKenry PC. The relationship between marriage and psychological well-being: A longitudinal analysis. J Fam Issues. 2002;23:885-911. doi:10.1177/019251302237296

9. Stahl ST, Beach SR, Musa D, Schulz R. Living alone and depression: the modifying role of the perceived neighborhood environment. Aging Ment Health. 2017;21:1065-71. doi: 10.1080/13607863.2016.1191060.

10. Theeke LA. Predictors of Loneliness in U.S. Adults Over Age Sixty-Five. Arch Psychiatr Nurs. 2009;23:387-96. 
doi:10.1016/j.apnu.2008.11.002

11. Bourassa KJ, Memel M, Woolverton C, Sbarra DA. Social participation predicts cognitive functioning in aging adults over time: comparisons with physical health, depression, and physical activity. Aging Ment Health. 2017;21:133-46. doi:10.1080/13607863.2015.1081152.

12. Ownby RL, Crocco E, Acevedo A, John V, Loewenstein D. Depression and risk for Alzheimer disease: Systematic review, meta-analysis, and metaregression analysis. Arch Gen Psychiatry. 2006;63:530-8. doi:10.1001/archpsyc.63.5.530.

13. Perlmutter M, Nyquist L. Relationships between self-reported physical and mental health and intelligence performance across adulthood. J Gerontol. 1990;45:P145-55. doi:10.1093/geronj/45.4.P145

14. Zelinski EM, Crimmins E, Reynolds S, Seeman T. Do medical conditions affect cognition in older adults? Health Psychol. 1998;17:504-12. doi:10.1037/0278-6133.17.6.504

15. Holtfreter K, Reisig MD, Turanovic JJ. Depression and infrequent participation in social activities among older adults: the moderating role of high-quality familial ties. Aging Ment Health. 2017;21:379-88. doi:10.1080/13607863.201 5.1099036

16. Penninx BWJH, Milaneschi Y, Lamers F, Vogelzangs N. Understanding the somatic consequences of depression: Biological mechanisms and the role of depression symptom profile. BMC Med. 2013;11:129. doi:10.1186/1741-7015-11-129

17. Ferreira Agreli B, Aparecida Dias F, Dos Santos Ferreira PC, Cândida Gomes N, Dos Santos Tavares DM. Functional disability and morbidities among the elderly people, according to socio-demographic conditions and indicative of depression. Invest Educ Enferm. 2017;35:48-58. doi: 10.17533/udea.iee.v35n1a06.

18. Almeida $L$, Quintão $S$. Depressão e ideação suicida em idosos institucionalizados e não institucionalizados em Portugal. Acta Med Port. 2012;25:350-8.

19. Vaz-Serra A, Firmino AC. Estados de tensão emocional, solidão e sintomas depressivos na população em geral. Psiquiatr Clin. 1989; 10: 149-15.

20. Caldas de Almeida J, Xavier M. Estudo Epidemiológico Nacional de Saúde Mental (Vol. 1). Lisbon: NOVA Medical School; 2013.

21. Sousa M, Nunes $A$, Guimarães $A$, Cabrita JM, Cavadas LF, Alves NF. Depressão em idosos: Prevalência e factores associados. Rev Port Clínica Geral. 2010. doi:10.32385/rpmgf.v26i4.10764

22. Oliveira-Brochado F, Simões $M R$, Paúl C. Inventário de Depressão de Beck (BDI-II) [Beck Depression Inventory (BDIII)]. In: Almeida LS, Simões MR, Gonçalves MM, editors, Instrumentos e contextos de avaliação psicológica. Coimbra: Almedina Edições; 2014. Vol. II; p. 189-212.

23. Gonçalves-Pereira M, Prina AM, Cardoso AM, da Silva JA, Prince $\mathrm{M}$, Xavier $\mathrm{M}$. The prevalence of late-life depression in a Portuguese community sample: A 10/66 Dementia Research Group study. J Affect Disord, 2019; 246: 674-81. doi: 10.1016/j.jad.2018.12.067.

24. Yesavage JA, Brink TL, Rose TL, Lum O, Huang V, Adey $M$, et al. Development and validation of a geriatric depression screening scale: A preliminary report. J Psychiatr Res. 1982;17:37-49. doi:10.1016/0022-3956(82)90033-4

25. Barreto J, Leuschner A, Santos F, Sobral M. Escala de Depressão Geriátrica [Geriatric Depression Scale]. In: Mendonça A, Guerreiro M, Grupo de Estudos de Envelhecimento Cerebral e Demências, editors. Escalas e testes na demência. Lisboa: Novartis; 2008. p. 69-72.

26. Firmino $H$, Simões MR, Pinho MS, et al. Addenbroke Cognitive Examination (ACE-R): Manual. Coimbra: Serviço de Avaliação Psicológica da Faculdade de Psicologia e de Ciências de Educação da Universidade de Coimbra; 2010.

27. Pachana NA, Byrne GJ, Siddle H, Koloski N, Harley E, Arnold E. Development and validation of the Geriatric Anxiety Inventory. Int Psychogeriatr. 2007;19:103-14. doi: $10.1017 /$ S1041610206003504
28. Ribeiro O, Paúl $C$, Simões MR, Firmino H. Portuguese version of the Geriatric Anxiety Inventory: transcultural adaptation and psychometric validation. Aging Ment Health. 2011;15:742-8. doi: 10.1080/13607863.2011.562177.

29. Simões MR, Firmino H. Geriatric Depression Scale (GDS30). Coimbra: Laboratório de Avaliação Psicológica e Psicometria, Faculdade de Psicologia e de Ciências da Educação da Universidade de Coimbra; 2013.

30. Ginó S, Guerreiro M, Garcia C. Escala de Queixas de Memória (SMC) [Memory Complaints Scale (SMC)]. In: Mendonça A, Guerreiro M, Grupo de Estudos de Envelhecimento Cerebral e Demências, editors. Escalas e testes na demência [Scales and tests in dementia]. Grupo de Estudos de Envelhecimento Cerebral e Demência. $2^{\text {a }}$ ed Lisboa: Novartis; 2008. p. 117-120.

31. Schmand B, Jonker C, Hooijer C, Lindeboom J. Subjective memory complaints may announce dementia. Neurology. 1996;46:121-5. doi:10.1212/WNL.46.1.121

32. Mioshi E, Dawson K, Mitchell J, Arnold R, Hodges JR. The Addenbrooke's Cognitive Examination revised (ACE-R): A brief cognitive test battery for dementia screening. Int $\mathrm{J}$ Geriatr Psychiatry. 2006;21:1078-85. doi:10.1002/gps.1610

33. Folstein MF, Folstein SE, McHugh PR. "Mini-mental state". A practical method for grading the cognitive state of patients for the clinician. J Psychiatr Res. 1975;12:189-98. doi:10.1016/0022-3956(75)90026-6

34. Guerreiro M, Silva A, Botelho M, Leitão O, Castro Caldas A, Garcia C. Adaptação à população portuguesa da tradução do "Mini Mental State Examination" (MMSE). Sinapse. 1994. doi:10.1017/CBO9781107415324.004

35. Nasreddine ZS, Phillips NA, Bédirian V, et al. The Montreal Cognitive Assessment, MoCA: A brief screening tool for mild cognitive impairment. J Am Geriatr Soc. 2005. doi:10.1111/j.1532-5415.2005.53221.x

36. Simões MR, Freitas S, Santana I, et al. Montreal Cognitive Assessment (MoCA): Versão final portuguesa [Montreal Cognitive Assessment (MoCA): Portuguese final version]. Coimbra: Serviço de Avaliação Psicológica, Faculdade de Psicologia e de Ciências da Educação da Universidade de Coimbra. 2008.

37. Alves L, Simões MR, Martins C. Teste de Leitura de Palavras Irregulares (TeLPI). In: Simões MR, Santana I, Grupo de Estudos de Envelhecimento Cerebral e Demência (GE$E C D)$, editors. Escalas e testes na demência $3^{\mathrm{a}}$ ed. Lisboa: Novartis; 2015. Vol.1, p. 50-56.

38. Garrett C, Santos F, Tracana I, et al. Avaliação Clínica da. In Mendonça A, Guerreiro M, Grupo de Estudos de Envelhecimento Cerebral e Demência, editors. Escalas e Testes na Demência. $2^{\mathrm{a}}$ ed. Lisboa: Novartis; 2008. p. 41-68.

39. Freitas S, Simões MR, Alves L, Santana I. Montreal Cognitive Assessment (MoCA): Normative study for the Portuguese population. J Clin Exp Neuropsychol. 2011;33:98996. doi:10.1080/13803395.2011.589374

40. Freitas S, Simões MR, Alves L, Santana I. The Relevance of Sociodemographic and Health Variables on MMSE Normative Data. Appl Neuropsychol. 2015;22:311-9. doi:10.1080 /23279095.2014.926455

41. Hughes $C P$, Berg $L$, Danziger $W L$, Coben LA, Martin RL. A new clinical scale for the staging of dementia. Br J Psychiatry. 1982;140:566-72. doi:10.1192/bjp.140.6.566

42. Instituto Nacional de Estatística. Portal de Estatísticas Oficiais. [accessed Jan 2020] Available from: http://www.ine. pt; 2017.

43. IBM Corp. Released 2013. IBM SPSS Statistics for Windows, Version 22.0. Armonk: IBM Corp.; 2013.

44. Cohen J. Statistical power analysis for the behavioural sciences. 2nd ed. Hillsdale: Lawrence Erlbaum Associates; 1988.

45. Jorm AF, Kelly CM, Wright A, Parslow RA, Harris MG, McGorry PD. Belief in dealing with depression alone: Results from community surveys of adolescents and adults. J Affect Disord. 2006;96:59-65. doi:10.1016/j.jad.2006.05.018 
46. Kessler RC, Birnbaum H, Bromet E, Hwang I, Sampson N, Shahly V. Age differences in major depression: Results from the national comorbidity survey replication (NCS-R). Psycho Med. 2010;40:225-37. doi:10.1017/S0033291709990213
47. Freitas S, Simões MR, Alves L, Santana I. Montreal cognitive assessment: Influence of sociodemographic and health variables. Arch Clin Neuropsychol. 2012;27:165-75. doi:10.1093/arclin/acr116 